\title{
HOW TO BE OR NOT TO BE? A CRITICAL DIALOGUE ON THE LIMITATIONS AND OPPORTUNITIES OF ACADEMIC DEVELOPMENT IN THE CURRENT HIGHER EDUCATION CONTEXT
}

\author{
K. Behari-Leak \\ Centre for Innovation in Learning and \\ Teaching \\ University of Cape Town \\ Cape Town, South Africa \\ e-mail: Kasturi-Behari-Leak@uct.ac.za
}

\section{N. Chitanand}

Centre for Excellence in Learning and Teaching

Durban University of Technology

Durban, South Africa

e-mail: nalinic@dut.ac.za

\section{K. Padayachee*}

School of Education

University of the Witwatersrand

Johannesburg, South Africa

e-mail: Kershree.Padayachee@wits.ac.za

\author{
J. E. Vorster \\ Centre for Higher Education, Teaching and \\ Research \\ Rhodes University \\ Grahamstown, South Africa \\ e-mail: j.vorster@ru.ac.za

\section{R. Ganas*} \\ Centre for Learning, Teaching and \\ Development \\ University of the Witwatersrand \\ Johannesburg, South Africa \\ e-mail: Rieta.Ganas@wits.ac.za
}

\section{Merckel}

Centre for Academic Staff Development

University of Johannesburg

Johannesburg, South Africa

e-mail: vanessam@uj.ac.za

\author{
L. Masehela \\ Centre for Higher Education Teaching and \\ Learning \\ University of Venda \\ e-mail: Mary.Masehela@univen.ac.za
}

\section{ABSTRACT}

In the tumultuous time we find ourselves, debates about pedagogy have taken centre stage once again. Concerns raised by the student protests of 2015 and 2016 have highlighted the urgent need to re-think traditional teaching, learning and assessment practices, as well as the development of decolonised and transformative curricula.

Traditional notions of academic and professional development are now being tested and contested, insofar as they are able to respond to student challenges in appropriate, responsive, legitimate and relevant ways. As a professional organisation dedicated to supporting learning and teaching, the executive team of HELTASA responded to the challenge in this article by engaging with perspectives on the purpose, role and conceptualisation of academic development in the current decolonial moment in the South African Higher Education landscape. Critical processes that enable academics to engage, share thoughts and debate epistemological, pedagogical and methodological options to support students and academics are much needed. And the context and spirit in which these debates occur may be as important as the debates themselves. 
At its annual conference, the executive team facilitated a critical dialogue with conference delegates on the limitations and opportunities of $A D$ in our current context. Given the diverse teaching and learning contexts and institutional differentiation in the sector, this article explores individual and collective theorised observations, reflections and experiences of the seven facilitators who led the $C D$. These reflections were analysed and discussed against the backdrop of $A D$ as well as the affordances of $C D$ as a participatory learning and engagement methodology. The findings showed that there is dire need to re-imagine, not only AD's role but alternative forms of critical engagement in the sector.

Keywords: contested, reflections, relevance, transformation, critical dialogues, engagement

\section{INTRODUCTION}

In these dynamic times in higher education (HE), with a strong concern for wellbeing at institutional and sector level, curriculum, pedagogy and assessment have taken centre stage in the calls for change by students across the sector. Concerns raised by the student protests of 2015 and 2016 highlighted the urgent need for the academy to rethink traditional teaching, learning and assessment practices. Traditional notions of academic and professional development are being contested, with questions raised about whether academic development (AD) is responding to student challenges in legitimate, transformative and relevant ways (Behari-Leak 2017; Vorster and Quinn 2015). At the same time, universities are being challenged to invest in the development of decolonised and transformative curricula. The academic teaching community especially is being challenged to provide more appropriate support and scaffolding for students and more deliberate and considered professional development programmes for academics as scholarly teachers (Leibowitz 2014; Mathieson 2011)

As a professional organisation dedicated to supporting learning and teaching and contributing to HE wellbeing, the Higher Education Learning and Teaching Association of Southern Africa (HELTASA), alongside institutional initiatives that are increasingly recognised by the Department of Higher Education and Training (DHET) and the Council on Higher Education (CHE), has the potential to play a role in engaging with these challenges, both conceptually and methodologically, to contribute to development. If enabling epistemological access and supporting student success are indeed the raison d'etre of an organisation like HELTASA, the executive committee felt it would be important to explore and interrogate the role of HELTASA in the context of the conversations and debates taking place currently in institutions and nationally about $\mathrm{AD}$ in $\mathrm{HE}$.

There is little doubt that higher education wellbeing is central to the work of academic development (Finley 2016). With a concern for change (Land 2001) through its commitment 
for "improvement and innovation" (Clegg 2009, 409) academic development has played a significant role in shaping teaching and learning and (educational) research in higher education institutions. But what does a "healthy" higher education system look like within our current contexts and what is AD's role in this? In unpacking this question, we had to consider the changing higher education context, the multiple forces impacting on this context and the impact of these on the well-being of higher education teachers, academic developers and our institutions. We were also cognisant of the important connection between higher education and well-being as illustrated by Haward $(2016,3)$ :

"The connections between higher education and well-being 'matter for the individual lives of the student and those who teach; they matter for the disciplines and professions; they matter for the institutions; they matter for the promise of a democratic civic society; and they matter for whether or not the unique and full promise of higher education - its greater purpose - can be advanced and realized'."

In considering its own wellbeing and the various national and institutional contextual changes, the HELTASA executive thought it would be appropriate to consider its own theory of change in light of students' and society's critique of the academy. Given the diversity in the sector, AD had assumed that institutional context, more than anything else, influenced our pedagogic choices but we needed to explore this by tackling some of our taken-for-granted assumptions as an organisation. We decided to convene and facilitate a critical dialogue (CD) session at the HELTASA 2017 annual conference hosted by the Durban University of Technology. We wanted to see if pedagogical and methodological options that value a plurality of social and cultural ways of being at the university, would gain traction with academic developers and teachers. We also wanted to see if and how HELTASA members and conference delegates were reflecting upon or re-imagining their own roles as $\mathrm{AD}$ and disciplinary practitioners at their institutions.

Critical dialogues (CDs) were introduced at the HELTASA 2017 conference as a participatory way of engaging with delegates on a "hot topic". The executive committee felt that it needed to engage with delegates in this "active mode" to inform its own work in service of its membership, thereby contributing to the organisation's well-being. Given the critique by protesting students that academic development makes hyper-visible the schism between those who can and cannot succeed at the university, (or those who do not succeed despite being potentially quite capable of doing so, but whose success is impacted upon by a multitude of non-academic challenges), it was envisaged that the $\mathrm{CD}$ would generate members' perspectives on the purpose and role of academic development (AD) in the current decolonial moment in the South African Higher Education landscape. We also wanted to facilitate a critical conversation 
with members on the limitations and opportunities of $\mathrm{AD}$ as a movement in the current decolonial context. Having the organisation's "ear to the ground" in this way would enable us to engage in robust discussions on national issues affecting our membership, in an informed manner.

In this article we outline the process we followed in conceptualising and facilitating a critical dialogue at the annual national conference. We reflect critically on our preparation, observations and experiences of being both observers and facilitators at the same time. We also offer perspectives on the emergent issues that were generated by the critical dialogue. In assessing the gains of the $\mathrm{CD}$, we consider the extent to which it did not work optimally and the possible reasons for this. As a collaborative process, we share what we have learnt about how a CD can open up spaces, (for what may be considered difficult and reflective conversations) but also close them down, depending on who is speaking and what the question or topic is.

\section{WHY AD? WHY NOW?}

Since its inception nationally as an "activist" movement in the 80's in SA, to support black students (Boughey 2010), AD has effected many gains. Institutional changes and policies demonstrate the significant role that $\mathrm{AD}$ research has played in shaping the learning and teaching landscape at institutions. Professional development programmes and post graduate diplomas in Higher Education have contributed to the theory and practice of academics in the classroom while empirical research has advanced the scholarship of teaching and learning overall. Academic developers, working in a liminal and hybrid third space (Behari-Leak and Le Roux 2018) serve on numerous committees, contribute to institutional projects and serve the academy in a myriad of roles, such as conference organisers, workshop facilitators, seminar leaders and the like. Interventions by academic developers have advanced a national recognition of the status and importance of teaching for student success and have contested the everyday discourse that "anyone can teach" to assert that the way disciplinary experts teach directly affects students' ability to succeed.

In South Africa the AD field emerged mainly as a response to less than ideal success and throughput rates of black students in historically white institutions. Boughey (2010) provides a detailed account of the evolution of the "activist" movement since the 1980s in South African higher education institutions until 2010. She identified several student support programmes put in place by different institutions as "adjunct" activities, not linked to the mainstream curriculum, in the form of tutorial support, language support, bridging or foundation courses and skills courses. It soon became evident that not only black students needed academic support 
but all students needed support in acquiring the academic literacies of various disciplines they studied. Furthermore, it was recognised that HE institutions were underprepared to offer the majority of students the kind of tuition they needed and that it was necessary to focus on academic staff development and curriculum development (Boughey and Niven 2012; Walker and Badsha 1993).

This led to the second phase of academic development which Boughey (2010) calls a "social turn". Colleagues in academic development realised there was more to academic support than targeting poor language skills in black students. There was a need to shift the focus from "the individual behaviour and individual minds to the social and the cultural and the way these are implicated in power" (Boughey 2010, 10). The second phase however failed to provide much in terms of transformation of universities and their development because of funding scandals (Boughey 2010). Questions remained as to whether academic development work had adopted a culture of compliance targeted at meeting the needs of globalisation and vocationalism (Boughey 2007) and propping up elitist normative educational worldviews.

The third phase of academic development came about in the early 2000's with the introduction of the National Qualifications Framework (NQF), outcomes based education (OBE), the establishment of new institutions as a result of mergers and institutional types, establishment of the Higher Education Quality Committee (HEQC) and eventually the establishment of a new funding framework which resulted in the three-year plan. It was during this stage that academic development practitioners began drawing on social theories to explain learning, which in turn led to the development of staff development initiatives. Winberg (2015) identifies five generations of academic staff development (ASD) that include a focus on technique/technology; student learning; reflective scholarly practice; ASD in the discipline; and an institutional view of academic staff development.

Despite the gains made, the main critique of $\mathrm{AD}$ in the current moment is that it has relinquished its original focus on HE as a social and public good (Manathunga 2011) and that it has lost its passion for political activism (Lee, Manathunga and Kandlbinder 2010, 316). Caught between a rock and a hard place, AD practitioners in differently structured and resourced centres and units, straddle roles of advocacy for $\mathrm{AD}$ work on the one hand and service to institutional management on the other, especially in the area of quality enhancement and implementation of language policies (Boughey and Mckenna 2016). A neo-liberal sensibility that seems to pervade HE might have also crept into our original modes of engagement, making us complicit and passive in different institutions. The need to self-reflect and challenge our own modus operandi is urgent and linked to demands of the current context which suggests that we 
might not have been as successful in driving the transformation agenda as we could / should have been. This is not an easy space to navigate, given the high stakes attached to AD's wellbeing, survival, identity and existence at the university in the first place. In its quest to selfprotect and retain staff and resources, it is possible that $\mathrm{AD}$ has become neutralised by bigger institutional structures that constrain the ability of academic developers and the field as a whole to maintain professional autonomy in the decisions made about teaching and learning.

Notwithstanding, in more one-to-one engagements and given our specialisation in supporting academic literacies through writing, reading and other productive practices, it is not surprising that AD practitioners "command" a disciplinary expertise that is sought after and respected by students and academic teachers alike, especially if this specialised support is solicited. It would be naïve if we believed that this expertise was not premised on an understanding of AD’s visible or invisible power. According to Roxå and Mårtensson (2016, 8), “academic developers are power-holders linked to expertise, institutional management, and policies, and through them the teachers encounter the language and perspectives of these forces, policies, and worldviews".

However, in the South African context some have long argued that through its various structural interventions such as writing centres, foundation courses and extended courses, AD carries and perpetuates the stigma of "deficit", making students feel "less than" and vulnerable (Vilakazi and Tema 1985; Mehl 1998). They further suggest that it is not students who are "underprepared" for the academy but the university itself, which has not changed its colonial matrices of power sufficiently to initiate processes and practices that make students (black students in particular) feel more "at home" (Tabensky and Matthews 2015).

While this critique flies in the face of the reason $\mathrm{AD}$ was established in the first place, it offers us a moment to pause and engage in deep introspection and reflection on what our initial role was and whether this role still serves the purpose it was created for. If we accept that as academic developers we operate from a powerful position, then is it possible that we can reengage this "power" for the public good? Roxå and Mårtensson (2016) suggest that conditions should be created for academic teachers to engage in a counter discourse or an alternative discourse about academic teaching and student learning, where academic developers could scaffold conversations and dialogues so that university teachers can become informed, critical and transformative, based on their authentic experiences in the classroom and their institutional contexts.

\section{WHY A CRITICAL DIALOGUE (CD)?}

It is well known in AD literature that critical dialogues are an effective mode of engagement 
because they provide a space for reflective educational practice (Mezirow 2000; Takeda and Marchel 2005). Since the inception of AD, reflective practice has been a signature methodology and pedagogy for academic and professional developers in the field. Dialogues, as a mode of engagement, have been used extensively in socio-cultural contexts to explore underlying patterns that influence aspects of working with diverse students and their epistemologies and ontologies. Dialogues are different to seminars, symposia and meetings which tend to engage in particular academic conventions and traditions that may be exclusive and exclusionary because only certain voices, and often those with the cultural capital or discursive ability to engage, can enter or stay. The strength of a dialogue is not only that it is a two-way, reciprocal conversation but it is prompted by a dialectic or critical question or problem that needs to be explored. The criticality needed and implied in "critical dialogue" is linked to its roots in critical theory and as such offers an invitation to participants and facilitators to discuss not only the question at hand, but the question in relation to social issues of power, privilege, gender, ethnicity, class, race and so on.

"Where a critical dialogue differs from reflective practice is that it "pays particular attention to the role of personal bias, especially with regard to patterns of power and privilege'." (Marchel 2007, 2).

In civil society, personal and implicit biases lead to discrimination against people, even though these are unconstitutional and, in many cases, punishable by law (Angela Davis Talk 2018). Similarly, protesting students in the \#MustFall movements in South Africa have cautioned that implicit biases play out in HE classrooms daily, in the way students are assessed and spoken to by lecturers and peers and by the deficit discourses that continue to construct them as "less than" (Kessi 2015).

Taken-for-granted assumptions are critical for academic developers and teachers to uncover and suspend, and possibly disrupt, especially in the current decolonial moment when students are asserting that they feel marginalised, invisible and unheard by the dominant culture at the university (Kessi 2015). Unchecked biases, which are often tacit to the person drawing on them, can lead to dire consequences for students. In a quest to "hunt" our assumptions (Brookfield 1990), or to catch them unaware, if you like, a critical dialogue, if facilitated well, can begin the process of laying bare the hegemonic beliefs and practices that influence our routine actions as teachers.

The critical dialogue also allows for a collaborative process in which "peers assist each other in mutual examination of biases" (Marchel 2007, 3). The benefits of a group process, given our diverse personal and situational contexts, are often underestimated if one is always 
or mainly involved in self-analysis and self-reflection on teaching. When one is critically reflecting on markers of difference such as race, class, gender, sexuality, ableism and so on, markers that privilege and value certain beliefs and attitudes in our current social contexts - the relational aspects of a dialogue among people who are different to oneself, has enormous potential, according to Marchel (2007), to enrich and broaden the thrusts of the dialogue and its potential for shifts in perspectives for participants in social contexts.

Brazilian educationalist, Paulo Freire (1990) popularised the CD in educational settings to connect it with meaningful changes in thinking with an awareness of social contexts and the call for political action. The spoken word and language are seen as media for critical reflections to take place in a collaborative space. An American phrase that has garnered popularity in the current and local context is "speaking truth to power". Coined by Quaker activists in the 1950s, this phrase which has taken root in public discourse and found its way into academia, refers to a new way of speaking the truth to advance a different kind of power. It advocates taking a stand to mobilise society around change but with the emphasis on "speaking"; it is a powerful, nonviolent challenge to injustice which is reliant on the premise of "courage" (Green n.d.). Linked to this, is the notion of "courageous conversations" which is a tool that has been used to resolve relational conflicts. For those who feel they are not heard, or that their perspectives and positionalities are not acknowledged, courageous conversations encourage empathic listening to facilitate deeper communication. Critical dialogues, therefore, as a mode of engaging with criticality, truth, power and courage, are a powerful way of tackling the difficult questions of our time.

As critically reflective practitioners ourselves, we are aware of the implicit danger to participants' sense of emotional safety if the CD is not facilitated in a responsible way. This means that guidelines have to be communicated clearly about the importance of respect and care especially since CD engages with vulnerability and frailty/ fragility across a spectrum of emotional and affective responses and reactions.

If $\mathrm{CD}$ is understood as an emergent interaction, facilitators have to understand that their role is to create enabling conditions for best possible outcomes to the question of exploring or solving a problem together. Following a critical realist (Bhaskar 1998) understanding, one has to accept that what is generated is "organic", resulting from sets of properties and powers that constitute both the structural, agential and cultural influences and mechanisms at play in the group setting (Archer 2000). As such, facilitators can influence how things are said but not what people say. Content cannot be curated as one would do in a structured interview or survey for example. This aspect makes the CD process alive and active, with great possibilities for agency and change. 


\section{METHODOLOGY}

As the HELTASA executive team, and as a group of facilitators, our reason for choosing the form and shape (genre) of the $\mathrm{CD}$ as a methodological process arose from our observations that academics relish the space and time to just talk. Whether it is to share theory or commiserate with each other about the stresses of teaching large classes or throughput rates or the intrusive use of mobile devices in class, academics seek a platform and space to share thoughts with peers in an informal way. The $\mathrm{CD}$, while structured and organised, allows for an informal exchange of ideas among participants. As academic developers and teachers, we can attest to the need to develop more spaces and time for stimulating discussion and debate on current challenges in HE.

Placing $\mathrm{AD}$ at the centre of focus of the $\mathrm{CD}$, we were interested in engaging HELTASA members (also conference delegates and participants in the CD reported on here) in our capacity as members of the executive committee. In 2016, the HELTASA executive re-imagined its role as critical agents in the organisation to exercise our agency in ways that encompass our personal and professional selves. Our assertion as a collective agency in the 2017 conference to engage in a scholarly yet dialogical way offers a counter narrative to the perception that organisational work revolves mainly around operational and logistical matters pertaining to the entity. As academics, we wanted to engage members in a professional area of practice central to them as well as to the organisation but also relevant to a HE context that has been called upon to decolonise itself. By resisting the "service" role, we were stretching ourselves to decolonise our own work and practice as the executive team. We have written about this approach elsewhere (The Conversation 2017) and it is through this re-conceptualisation of the traditional roles handed down, that we contest that which has become normalised and internalised in the academy. In this instant, we also challenged the trope that AD work in the academy, much like organisational work in HELTASA, is feminised, care-work, and best left to women who are natural care-givers. In charting a new course, we assert that we cannot continue to be the proverbial "hand maidens" to mainstream academic action, decision making and debate, typically associated with men and the role they play in organisations, in HE and in AD.

In defining and identifying the main problematic for the $\mathrm{CD}$, the members of HELTASA executive team took on the role of facilitators and were asked to generate a series of critical questions emerging from their own contexts. Through a collaborative process of discussion and comments on the issues that were raised, the $\mathrm{CD}$ was theorised and conceptualised to take into consideration the thematic focus of the conference, namely, "HE well-being".

After the initial list of questions was generated, the $\mathrm{CD}$ facilitators were asked to identify 
the most salient questions and those that resonated with them; then to choose specific questions to explore further. Each person was given an option to team up with someone else where the topic was too broad and to challenge some of the taken-for-granted assumptions that they held. While the aforementioned list was intended to guide the actual CD process on the day, two pretask questions were sent to those attending the $\mathrm{CD}$ before-hand, as preparation for the discussion that would ensue:

- $\quad$ Can $\mathrm{AD} / \mathrm{ED}$ as a higher education field and movement be explicit about its social and contextual purpose without losing academic credibility?

- $\quad \mathrm{Can} /$ should AD re-invent itself to become more central to the process of transformation unfolding at universities currently?

We chose a conversation style format for the dialogue, known as the Knowledge Café or World Café methodology (http://www.conversationcafe.org), renowned for its use in community settings to stimulate debate, discussion and action on critical issues facing the community. Dialogue, as it is used in the Knowledge Café is not merely about people talking - it is about what (content) and how they talk (process), how they engage and how they choose moments of silence as well.

According to Knowledge Café proponents (Gurteen 2012; Singh 2017) dialogue is a conversation that takes place in a facilitated, structured circle about a meaningful topic, question or shared experience. It requires mutually agreed upon guidelines such as respect, deep listening, open mindedness, suspension of judgments and confidentiality. Dialogue is an invitation to share, discover new insights, deepen our understanding of ourselves and one another, express love and compassion, stimulate creative thinking, activate the imagination, evoke collective wisdom, build community, and inspire cooperative social action. The process recognises the equal value of all participants; it provides safety to question assumptions and those of others; it supports exploration of new insights; and it allows for uninterrupted speaking and reflective silence.

\section{FACILITATING THE CONVERSATION CAFÉ}

As dialogue facilitators, we sought to adhere to the basic guidelines or principles advocated by the Café. Firstly, we had to set the context by explaining the objectives, themes and questions. We understood the importance of creating a hospitable space because when people feel safe and comfortable to be themselves, they do their most creative thinking, speaking, and listening (Marchel 2007). We then presented our questions to the participants in different conversational 
rounds, allowing groups to dialogue about one question at a time at their table, with assistance from us as facilitators. As academic developers by training, we understood the importance of participation but also of the need of those who participate by listening first and then joining in later. Therefore, as facilitators of the $\mathrm{CD}$, we had to suspend our own assumptions and judgements and allow the conversations to flow.

The café method enabled people to connect different views as questions and thoughts, ideas and perspectives travelled across the room. Through listening and paying attention to themes, patterns and insights, we, as a group of facilitators began to get a sense of a connection to the larger whole through the issues that bind us but also through the issues that were not being spoken about. The last phase of the Café, called the "harvest", brought it all together with participants reflecting on the deeper questions experienced in the small group conversations in plenary.

\section{ABOUT THE FINDINGS AND DISCUSSION SECTION}

We have chosen a novel way to explore the data in this article. Instead of "data excerpts" to support the claims we make, our reflections on the CD process become the data and are presented as such. In addition, we decided to use an example of a knowledge café in this article to provide a sense of the knowledge café process used in the $\mathrm{CD}$. We present each round of the $\mathrm{CD}$ with a topic/ set of questions; we then unpack how the executive committee of HELTASA understood the question; thereafter we share our individual and collective insights gleaned from the participants' group discussions at the tables where we served as facilitators. Our insights serve as the "data" in this article and are captured in our reflections on what emerged from the CD. The snapshots shared here of the emergent themes and ideas generated in the CD by participants, also form part of our data set. We will then offer a discussion and analysis of the $\mathrm{CD}$ process and we conclude by giving our account of the success or limitations of this $\mathrm{CD}$ in achieving its goals.

The sets of questions that were given to groups in each of the five conversational rounds of the CD process, are now discussed individually in the next section.

\section{FINDINGS AND DISCUSSION}

The first round of the $\mathrm{CD}$ presented as a background and overview of $\mathrm{AD}$ and its historicity as a movement in this country till the present moment. This was necessary to bring everyone to a common departure point as $\mathrm{AD}$ is a diverse field and draws on an eclectic set of frames of reference. Much of the input in this round has been discussed above (see Why AD? Why now?). Academic development's forty to fifty-year history is a relatively short period, during which there has not been enough time for $\mathrm{AD}$ to establish itself as a strong professional field, 
especially because the field has mainly operated on the margins of universities (Boughey and Volbrecht 2004). Only in the last twenty years or so, have some institutions offered permanent positions to academic developers while others still provide short-time contracts. Insecure employment conditions, casualisation and instability of the workforce has meant that there are a limited number of professionals with a deep understanding of the historical development of the field (Vorster and Quinn 2015) to strengthen its stability. One of the unfortunate results of this unstable and interrupted trajectory has been the frequent reinvention of ideas and practices in the field, based on common-sense and intuition and thus not particularly fit for purpose.

\section{THE SECOND ROUND OF THE CD: WHAT ARE THE IDEOLOGICAL AND PHILOSOPHICAL UNDERPINNINGS OF AD AND WHAT ARE ITS BLIND SPOTS?}

By engaging with the AD literature (Van Wyk and Higgs 2004; Little and Green 2012; Boud and Brew 2013; Gibbs 2013; Kinash and Wood 2013; Leibowitz 2014; Mårtensson 2015; Knapper 2016) and drawing on our own contextual and conceptual knowledge, the first pair of facilitators established the philosophies and ideologies of AD. These included social justice; redress and equity; human dignity; democratization; quality; effectiveness and efficiency; public accountability; institutional autonomy and human resource development, thus mirroring the philosophies and ideologies of HE. This premise became our "baseline" for discussion in the $\mathrm{CD}$. Input to the group focused on academic development fulfilling a particular purpose within the wider HE context. The challenge of being a mirror is that, as the facilitators noted, when shifts occurred in $\mathrm{HE}$, it seemed that $\mathrm{AD}$ followed closely, responding to the challenges, problems and dilemmas of the sector, instead of leading the way with theorised and practical interventions and "solutions". In the last three years, AD practitioners have had to quickly reinvent themselves and their roles and purposes to remain institutionally relevant. Emerging from the $\mathrm{CD}$ was the view that while $\mathrm{AD}$ can respond and be agential, and has made many gains in this regard, $\mathrm{AD}$ is not unanimously perceived by $\mathrm{HE}$ as a key agent of change. In most cases, the groups in the $\mathrm{CD}$ felt that the general academic community tends to view $\mathrm{AD}$ as institutional "fixers" and "trouble shooters" who could be called on, not as leaders in the field, but as practitioners to whom others turn when in crisis. The deeper question of whether AD had been standing on its own philosophical and ideological underpinnings and leading from this position of strength or following the pace set by HE by responding only when asked to, persisted.

Based on the outcomes of the $\mathrm{CD}$ group discussions, we concluded that although $\mathrm{AD}$ is strongly underpinned by notions of social justice and human dignity, equity and redress, quality enhancement and human resource development for teaching and learning success, AD 
practitioners, due to constraints, often tend to operate in a mechanistic and reactive manner at the margins of the academic project (Little and Green 2012; Manathunga 2007). These perspectives helped to shape our understanding as the executive team of HELTASA to recognise the need to claim a space within the HE sector as proactive agents of change, to position ourselves not only as bridge builders and hand-holders but as learning partners with institutions, with the aim of preparing resourceful human capacity for advancement of teaching and learning in Higher Education.

\section{THE THIRD ROUND OF THE CD: WHAT PEDAGOGIES MIGHT ENHANCE THE ENVISAGED CHANGES? WOULD SOCIALLY JUST OR DECOLONIAL PEDAGOGICAL PRACTICES SERVE THIS END?}

On the issue of relevant pedagogies, there was consensus among the $\mathrm{CD}$ groups that $\mathrm{AD}$ has skilfully used its identity both as a field of practice and an academic field (Higher Education Studies being the academic field from which academic development draws its knowledge), to draw on a rich range of theorised options directly related to effective teaching and learning pedagogy. Groups felt that even though its most vigorous internal struggle relates to the epistemological bases of its work, the challenges that come with being an eclectic field, and the claim that it does not have a strong "epistemological spine" (Shay 2012), AD has been able to draw on relevant theories that provide not only strong explanations for why things are the way they are, but a solid basis for pedagogical practices based on social constructivist theories, academic literacies, critical theory and discourses, and ways of thinking, writing, acting and being in HE (Barnacle and Dall'Alba 2017).

This does not mean there are no pedagogical challenges. Our most recent history has pointed to at least one of our blind spots. The student protests of 2015 and 2016 and calls for the decolonisation of higher education have given academic developers cause to think about what may have gone wrong in our endeavours to create the most fertile conditions for enabling epistemological access for most students. The groups came to understand that because our gaze was focused on particular places, we failed to see other vistas that clearly did not escape the vision of many students. So, while there needs to be a focus on strengthening the epistemological spine of our field, it is also necessary to be maintain a measure of epistemological openness so that we can see alternative and more diverse ways of viewing our field and our practice.

In the $\mathrm{CD}$, there was also a recognition that hegemonic beliefs undergirding traditional practices in HE, are underpinned by profoundly different histories, positions and varied 
privileges which are often related to "pain" which might work against our well-being. This pain is experienced as marginalisation and silence, the potential disruption of our closely held assumptions and the discomfort that results from this. Students have alerted us to the reality that the presence of "pain" in the classroom, though not always easy to engage with because it often leads to a tendency to feel "at risk" and vulnerable, is a necessary contradiction, as it ironically creates fertile grounds for transformation, growth, learning and well-being. "Learning from another's pain requires noticing what one has not experienced and the capacity to be touched by what one has not noticed; identifying with the pain requires a self, capable of wounding his or her own boundaries, the very boundaries that serve against pain" Britzman $(2000,30)$.

Emerging from the groups was the question of whether AD practitioners can create spaces for this discomfort to occur despite the perceived risks of dis-engagement. In other words, how do we make this pain educative in a way that makes it possible for all to grow? This question implies a willingness and readiness to address and embrace "the status of our susceptibility to histories we do not live, to stories that disturb one's sense of cohesiveness" Britzman (2000, 35). Although the CD explored one or two pedagogical methods that could be used to create a safe enough space to work with a focus on intelligent judgment, inquiry, and investigation with an open heart and an inquiring mind, these were difficult questions for the participants to engage with. It became clear that this is the very area in $\mathrm{AD}$ that needs further exploration, development and theorisation so that we can begin to think about different pedagogies that enable us to work in these rich ways. This would strengthen AD to simultaneously occupy precarious and tentative spaces to honour all in the dialogue, but to also explore the dialectical balance between knowing, being and becoming (Barnacle and Dall'Alba 2017).

\section{THE PEN-ULTIMATE ROUND OF THE CD LINKED DIRECTLY TO THE CONFERENCE THEME: HOW DO WE, AS HIGHER EDUCATION TEACHERS}

\section{AND ACADEMIC DEVELOPERS, MANAGE OUR OWN WELL-BEING AND THAT OF OUR INSTITUTIONS?}

Well-being is a complex construct and may be associated with human flourishing and a life well lived (Haward 2016). Its connection to higher education, however, has not received the attention that is perhaps needed to advance the greater purposes of higher education. As a university-in-becoming (Waghid 2017), higher education institutions are at the forefront of educational and social development while at the same time subject to myriad educational and social changes and challenges. Globalisation, massification, the fourth industrial revolution and 
increased focus on performativity have impacted significantly on higher education policies, practices and approaches. How higher education teachers and academic developers negotiate these changing conceptions and practices of/in higher education to ensure their own well-being and those of their institutions was the focus of this segment of the CD. While the challenges alluded to above impact on the who, what, how, why and where of teaching, learning and research in higher education, it also impacts on how we as higher education teachers and academic developers live and work. It impacts on our being and our well-being (Barnacle and Dall'Alba 2017). It impacts on how to be or not to be in higher education in the $21^{\text {st }}$ century and beyond.

A number of themes discussed below emerged through the $\mathrm{CD}$ on the well-being of higher education teachers, academic developers and our institutions. As a field, academic development tends to face both ways: leaning towards achieving transformation, social justice and critical citizenry through $\mathrm{HE}$, while at the same time contributing to improving the quality of teaching and learning (even if in a somewhat piecemeal and technical way at times) to show immediate impact (Di Napoli 2014). In an increasingly neoliberal higher education context, the overemphasis on hegemonic performativity and efficiency discourses impacts on the quality of academic development work and its transformative agenda in significant ways (Barnacle and Dall'Alba 2017). A corollary to this is the question of how "academic developers position themselves if their own values do not reflect the social and institutional discourses of their workplace?" (Di Napoli 2014, 4). This in turn influences not just the wellbeing of practitioners but the institution, the profession and society at large.

The discussion emerging from the CD showed that the wellbeing of academic developers is seriously impacted and affected by issues of identity and legitimacy, considered to be attributed to the apparent "youthfulness of the field" (Baume and Popovic 2016, 9). As a field "coming of age" (Lee, Manathunga and Kandlbinder 2010), academic development remains an under theorised field of endeavour (Boud and Brew 2013; McKenna 2014; Shay 2012; Vorster and Quinn 2015), but as we build knowledge to ensure the wellbeing in/of the field of academic development, are we at risk of alienating the very people with whom we work and serve (our students, our staff and managers). How does this impact on their well-being and that of our institutions? Or are we contextualised and inclusive as we would like to think?

Within this growing field, academic developers are fraught with challenges. One of these challenges relates to being considered a "family of strangers" (Harland and Staniforth 2008) with "unhomely identities" (Manathunga 2007). Academic developers have had to work on the margins "betwixt and between" managers and academics (Little and Green 2012). These hybrid 
identities coupled with a struggle to be considered as legitimate role players within higher education have resulted in academic developers occupying chameleon like existence (Kensington-Miller, Renc-Roe and Morón-García 2015; Van Schalkwyk and McMillan 2016). Engaging in legitimate discomfort and giving voice to these arguments in our classrooms and academic development spaces as well as practising a decolonisation of our own minds may offer a disruption of deeply seated assumptions and pre-conceptions needed for our own wellbeing. Care and love for each other and our work and sincerity in building relationships between academic developers and higher education teachers can provide the empowering spaces needed to achieve our goals in higher education, amidst the chaos, ensuring our well-being.

\section{THE FINAL ROUND OF THE CD: HOW DO WE TRANSCEND OUR OWN DISCIPLINARY AND INSTITUTIONAL BOUNDARIES TO BECOME EFFECTIVE CHANGE AGENTS IN THE SECTOR?}

In our collective experience, there is little by way of formal induction into or accreditation for practising in the field of AD. Academic developers either work in specialist centres such as teaching and learning centres, writing centres or reading laboratories; or teaching and learning specialists are attached to an academic department, school or faculty. In some cases, they manage student development programmes such as mentoring, tutoring or Supplemental Instruction programmes. Newcomers learn through being mentored by experienced colleagues and through being directed to favoured texts about the field or a specialism. Staff developers offer formal programmes such as postgraduate diplomas in higher education, and / or short learning programmes and ad hoc workshops. Academic development is thus diverse in its practices and in the way it is organised.

Through the CD it emerged that the diversity of the field is both a strength and a source of challenge. A positive aspect of the field is that it is dynamic, with new areas of focus emerging as the higher education context changes. However, the diversity in the field means that it sacrifices coherence in terms of its axiological, epistemological and methodological underpinnings. Like every other field in the academy, academic development is a site of struggle. The objective of epistemological access for the majority of university students through equitable access with success is counterbalanced with the academy's need for efficiency. A significant proportion of university funding is dependent on student success, and the staff and student development work of academic developers is required to contribute to achieving or maintaining reasonable success rates. So, the values that frame academic development practices include sometimes contradictory ideas that are clumped together such as transformation, 
decolonisation, social justice, equity, redress, quality, efficiency, effectiveness, assimilation, reflective practice.

There is considerable variation in approaches to and methods of engaging in academic development work in South Africa. Some of the differences are ideological while others are practical. For example, the scope of staff development opportunities available to academics whether staff development is offered as short, stand-alone workshops or short courses or as part of a coherent staff development programme - depends on the extent to which an institution values teaching in relation to research. Sometimes, though, these kinds of choices are made for practical reasons - if an institution does not, for example, have suitably qualified or experienced academic developers, and is therefore not able to offer theoretically sound and practically useful staff development initiatives. In a similar vein, decisions about the kind of student development that is most appropriate for the context also depends on a combination of espoused values, theoretical stances and what is practically possible.

In responding to the question about $\mathrm{AD}$ and its agency, it emerged that everyone who is concerned about and interested in building the field of academic development has an obligation, both to themselves as professionals and to the field, to get to know the field, its history, its knowledge base, its struggles and debates, its values, and its practices. There is a wealth of knowledge about how best to induct students into the knowledge practices of the different disciplines they study; similarly, there is much to learn about the best ways to engage with academics about curriculum, pedagogy, assessment and about being a teacher in higher education. It is necessary to use the most robust theories and methods to get to know and to grow the field as they offer the greatest explanatory power for why things are the way they are and they offer ways of thinking about how things can be made better. One way of strengthening the field and building cumulative knowledge about academic development is through collaboration. Involvement in the various activities of HELTASA such as annual conferences, and the special interest groups is an imperative for advancing a shared understanding of the field. Another pertinent issue relates to the kinds of policies academic developers contribute to, develop and promote. It is important that we consider our motives for engaging in policy development and promotion, and that we understand the possibilities of what policies can achieve as well as the limits of policy. We should also not be blind to the likelihood that there may be policies that may have unintended and even undesirable consequences.

\section{CONCLUSION}

The last few years in South African HE, marked by student protests and the "decolonial turn", 
have disrupted our current conceptions about HE and pulled academic development into a central position with academic developers and academics negotiating new understandings in an attempt to alleviate "pedagogic frailty" (Vorster and Quinn 2017). Through the themes and perspectives that emerged from the $\mathrm{CD}$, as discussed above, we conclude that the $\mathrm{CD}$ was an effective pedagogical engagement that enabled us to create a space in which we could "critique the underlying ways of thinking and acting in higher education through a reflexive approach" (Brew 2007) to our work. This reflexivity forced us to ask critical questions about ourselves as academic developers and of the field of $\mathrm{AD}$. The $\mathrm{CD}$ enabled participants as AD practitioners to cultivate a strong sense of the role of $\mathrm{AD}$ and a strong voice in which to articulate the value of the field and one's role in the field. Through the $\mathrm{CD}$, we were able to surface our values and how we are living them out within a complex, challenging and dynamic higher education context. In adopting this reflexive approach through the $\mathrm{CD}$, we were able to surface some of our understandings of the field, and we achieved a sense that much of what we know and believe about our field is shared among participants.

The critical dialogue itself proved to be an effective way of bringing a group of people together to have an open, creative conversation on a topic of mutual interest. Through the Knowledge Café, participants shared ideas to gain a deeper collective understanding of the subject and the issues involved. They left the dialogue with ideas to take back to their institutions. The CD gave the HELTASA executive team much to ponder and deliberate on, and the process enabled us to surface blind-spots in our thinking and our practices. This will, no doubt, shape our work further, especially regarding the unanswered questions which we need to critically engage with. One such question, which could herald a possible fourth phase of AD as a movement and a field, is: how can $\mathrm{AD}$ contribute to a transformative discourse and programme that engenders a greater critical social justice worldview within the higher education sector in South Africa today?

\section{REFERENCES}

Archer, Margaret S. 2000. Being human: The problem of agency. Cambridge: Cambridge University Press.

Barnacle, Ronald and Gloria Dall'Alba. 2017. Committed to learn: Student engagement and care in higher education. Higher Education Research \& Development 36(7): 1326-1338.

Baume, David and Ceila Popovic. 2016. Advancing practice in academic development. New York: Routledge.

Behari-Leak, Kasturi. 2017. New academics, new higher education contexts: A critical perspective on professional development. Teaching in Higher Education 22(5): 485-500.

Behari-Leak, Kasturi and Le Roux. 2018. Between a rock and a hard place. Perspectives in Education 36(1): 30-43. DOI: http://dx.doi.org/10.18820/2519593X/pie.v36il.3. ISSN 0258-2236e-ISSN 
Bhaskar, Roy. 1998. Philosophy and scientific realism. In Critical realism. Essential readings, ed. Margaret Archer, Andrew Collier, Tony Lawson and Allan Norrie, 16-47. Abingdon: Routledge.

Boud, David and Angela Brew. 2013. Reconceptualising academic work as professional practice: Implications for academic development. International Journal for Academic Development 18(3): 208-221.

Boughey, Chrissie and Terry Volbrecht. 2004. Curriculum responsiveness from the margins? A reappraisal of academic development in South Africa. In Curriculum responsiveness. Case studies in higher education, ed. Hanlie Griesel. Pretoria. SAUVCA.

Boughey, Chrissie. 2007. Marrying equity and efficiency: The need for third generation academic development. Perspectives in Education: Exploring the Surfaces and Depths of Quality Assurance 25(3): $1-11$.

Boughey, Chrissie. 2010. Academic development for improved efficiency in the higher education and training system in South Africa. Pretoria. Development Bank of Southern Africa.

Boughey, Chrissie and Penny Niven. 2012. The emergence of research in the South African academic development movement. Higher Education Research \& Development 31(5): 641-653.

Boughey, Chrissie and Sioux McKenna. 2016. Academic literacy and the decontextualized learner. Critical Studies in Teaching and Learning 4(2): 1-9.

Brew, Angela. 2007. Evaluating academic development in a time of perplexity. International Journal for Academic Development 12(2): 69-72.

Britzman, Deborah. P. 2000. If the story cannot end: Deferred action, ambivalence and difficult knowledge. In Between hope and despair: The pedagogical encounter of historical remembrance, ed. R. Simon, S. Rosenberg and C. Eppert, 27-57. Lanham, MD: Rowan \& Littlefield.

Brookfield, Stephen. 1990. Using critical incidents to explore learners' assumptions. In Fostering critical reflection in adulthood: A guide to transformative and emancipatory learning, ed. J. Mezirow and Associates, 177-193. San Francisco: Jossey-Bass.

Clegg, Sue. 2009. Forms of knowing and academic development practice. Studies in Higher Education 34(4): 403-416.

Di Napoli, Roberto. 2014. Value gaming and political ontology: Between resistance and compliance in academic development. International Journal for Academic Development 19(1): 4-11.

Finley, Ashley. 2016. Well-being: An essential outcome for higher education. Change: The Magazine of Higher Learning 48(2): 14-19. DOI: 10.1080/00091383.2016.1163163.

Freire, Paulo. 1990. Education for critical consciousness. New York: Continuum.

Gibbs, Graham. 2013. Reflections on the changing nature of educational development. International Journal for Academic Development 18(1)12: 4-14.

Green, John. n.d. Speak truth to power. https://classroom.synonym.com/origin-phrase-speaking-truthpower-11676.html

Gurteen, David. 2012. Leading issues in social knowledge management. Academic Publishing International Limited.

Harland, Tony and David Staniforth. 2008. A family of strangers: The fragmented nature of academic development. Teaching in Higher Education 13(6): 669-678.

Haward, Donald W. 2016. (eBook). Well-being essays and provocations: Significance and implications for higher education. In Well-being and higher education: A strategy for change and the realization of education's greater purposes, ed. D. W. Haward, 3-17.

Kensington-Miller, Barbara, Joanna Renc-Roe and Susan Morón-García. 2015. The chameleon on a tartan rug: Adaptations of three academic developers' professional identities. International Journal for Academic Development 20(3): 279-290.

Kessi, Shosi. 2015. Time to decolonise our universities. Black alumni panel discussion. Sunday 
Independent. UCT, April 7.

Kinash, Shelley and Kayleen Wood. 2013. Academic developer identity: How we know who we are. International Journal for Academic Development 18(2): 178-189.

Knapper, Christopher 2016. Does educational development matter? International Journal for Academic Development 21(2): 105-115.

Land, Ray. 2001. Agency, context and change in academic development. International Journal for Academic Development 6(1): 4-20.

Lee, Alison, Catherine Manathunga and Peter Kandlbinder. 2010. Shaping a culture: Oral histories of academic development in Australian universities. Higher Education Research \& Development 29(3): 307-318.

Leibowitz, Brenda. 2014. Reflections on academic development: What is in a name? International Journal for Academic Development 19(4): 357-360

Little, Deandra and David A. Green. 2012. Betwixt and between: Academic developers in the margins. International Journal for Academic Development 17(3): 203-215.

Mathieson, Susan, 2011. Developing academic agency through critical reflection: A sociocultural approach to academic induction programmes. International Journal for Academic Development 163: $243-256$.

Manathunga, Catherine, 2007. "Unhomely" academic developer identities: More post-colonial explorations. International Journal for Academic Development 12(1): 25-34.

Manathunga, Catherine, 2011. The field of educational development: Histories and critical questions. Studies in Continuing Education 33(3): 347-362.

Marchel, Carol A. 2007. Learning to talk/Talking to learn: Teaching critical dialogue. Teaching Educational Psychology Spring, Vol. 2.1.

Mårtensson, Katarina, 2015. Academic development - old habits or disruptive practice? International Journal for Academic Development 20(4): 303-305.

McKenna, Sioux, 2014. Higher education studies as a field of research. The Independent Journal of Teaching and Learning 9: 6-14.

Mehl, Merlyn. 1988. Academic support: developmental giant or academic pauper? South African Journal of Higher Education 2(1): 17-20.

Mezirow, Jack. 2000. Learning as transformation: Critical perspectives on a theory in progress. The Jossey-Bass Higher and Adult Education Series. San Francisco: Jossey-Bass.

Roxå, Torgny and Katerina Mårtensson. 2016. Agency and structure in academic development practices: Are we liberating academic teachers or are we part of a machinery supressing them? International Journal for Academic Development. DOI: 10.1080/1360144X.2016.1218883.

Shay, Suellen. 2012. Educational development as a field: Are we there yet? Higher Education Research \& Development 31(3): 311-323.

Singh, Shawren. 2017. The Knowledge Café as a research technique. The Electronic Journal of Business Research Methods 15(1): 29-40.

Tabensky, Pedro and Sally Matthews. (Eds.). 2015. Being at home: Race, institutional culture and transformation in South African higher education institutions. Pietermaritzburg. UKZN Press.

Takeda, A. and C. A. Marchel. 2005. A comparison of reflective practice with counselling practices in Japan and the United States. The Kanda University Journal of International Studies 17: 375-395.

Talk with Angela Davis. 2018. UCT Law Seminar.

Van Schalkwyk, Susan and Wendy J. McMillan. 2016. "I have a chameleon-like existence": A duoethnographic account of border crossing by two academic development practitioners South African. Journal of Higher Education 30(6): 207-223.

Van Wyk, Berte and Phillip Higgs. 2004. Towards an African philosophy of higher education: 
Perspectives on higher education. South African Journal of Higher Education 18(3): 196-210.

Vilakazi, Herbert. B. and B. Tema. 1985. White universities and the black revolution. Aspects: Journal of the Academic Support Programmes at the University of Cape Town, the University of Natal, Rhodes University and University of the Witwatersrand 6: 18-40.

Winberg, Christine. 2015. University teaching in changing times and contexts. Keynote address SoTL Conference, Stellenbosch 26 October.

Vorster, Jo-Anne and Lynn Quinn. 2015. Towards shaping the field: Theorising the knowledge in a formal course for academic developers. Higher Education Research \& Development 34(5): 10311044.

Vorster, Jo-Anne and Lynn Quinn. 2017. Re-framing academic staff development. In Pedagogic frailty and resilience in the university, ed. I. M. Kinchin and N. E. Winstone, 109-121. Rotterdam: Sense Publishers.

Waghid, Yusef. 2017. A university without ruins: Some reflections on possibilities and particularities of an African university. South African Journal of Higher Education 31(3): 1-5.

Walker, Melanie and Nasima Badsha. 1993. Academic development and the challenge of curriculum change at the University of the Western Cape: An overview. AD Dialogues 1: 1-14. 